\title{
obituary
}

\section{J. E. Littlewood}

Professor John Edensor Littlewood, FRS, Emeritus Rouse Ball Professor of Mathematics in the University of Cambridge, died on 6 September, 1977, at the age of 92 .

He was the son of Edward Thornton Littlewood, a schoolmaster who had been 9th Wrangler in 1882. Littlewood was taught mathematics at St. Paul's School by F. S. Macaulay, later FRS, an outstandingly successful teacher. Littlewood has described his mathematical education, including his early experiences in research, in $A$ Mathematician's Miscellany, and it seems to have been a far from ideal preparation for the kind of research which became his life. For Cambridge mathematicians had not yet fully appreciated the major advances on the Continent.

His director of studies, E. W. Barnes, suggested the problem of integral functions of zero order, in particular asymptotic formulae for functions with given zeros. Perhaps as a result of independent reading, Littlewood switched to 'elementary' methods for general functions and produced an important result in his first paper on the maximum and minimum moduli of any integral function of zero order, a type of result which Barnes had described in 1898 as 'a disguised truism'. However, Barnes now recognised the value of the work; one referee opposed publication violently, but G. H. Hardy reported favourably and the paper was published in 1907.

In 1911, Littlewood opened a new chapter in the theory of series with his Abel-Tauber theorem which led to his immensely important collaboration with Hardy lasting 35 years.
It covered, besides the theory of series, and in particular Fourier series, the Riemann zeta function, Diophantine approximation, the additive theory of numbers and the theory of functions.

After three years in Manchester, Littlewood returned in 1910 to a Fellowship and Lectureship at Trinity College; he became Rouse Ball Professor in 1928. During the First World War he worked as a Second Lieutenant on anti-aircraft ballistics. He retained his rooms in Trinity as Life Fellow until his death. He spent little of any vacation in Trinity, finding a different setting better for concentration on research. He believed that periods of complete relaxation were essential and often found them in music, and in rock-climbing and ski-ing.

In his younger days he served on the Councils of his College, the Royal Society and the London Mathematical Society, but from about 1935 the fits of depression which had plagued him for many years seem to have become worse. $\mathrm{He}$ took no part in meetings of committees or councils or in gatherings of mathematicians. However, his fits of depression were cured sometime in the $1950 \mathrm{~s}$, and he paid several highly successful visits to the U.S.A. after retiring.

A very high proportion of Littlewood's work after 1912 was done in collaboration with Hardy, some with Paley, Offord, myself and others. When Harald Bohr, brother of Niels Bohr, paid his first long visit to Cambridge, he and Littlewood wrote a monograph on the zeta function, but, when it was finished, they were so exhausted that they could not take it to the printers. The manuscript was used later by Titchmarsh and Ingham in writing their Tracts on the subject. Of the papers appearing under Littlewood's name alone, the one in 1925 made a very important contribution to the problem of the coefficients of functions schlicht in the unit circle, a problem still not completely solved.

Although in the early days there must have been many discussions with Hardy, most of their joint work was done by correspondence. It seems that there was an unwritten agreement that Hardy could write up and publish anything based on joint work, but Littlewood only allowed me to write up parts of our joint work on condition that it appeared under my name alone as 'based on joint work.' My own collaboration with Littlewood arose out of a D.S.I.R. memorandum on the nonlinear differential equations arising in radio work, and the most important result arose out of a letter to Nature 120 (1927), 363, by van der Mark and van der Pol on frequency demultiplication, or rather van der Pol's interpretation of it in Proc. Inst. Radio Engnrs 22 (1934), 1051-1086.

I used to go to Littlewood's lectures on the theory of functions; some of them are included in his book of that title, and at one time he used the galley proofs. Although he had given the same lecture two or three times before, he showed such a passionate interest, always seeing things from a slightly different angle, that his audience could not help sharing his enthusiasm.

Littlewood's display of unequalled insight, technique and power as an analyst, was recognised by honorary doctorates, medals and membership of leading foreign academies.

Mary L. Cartwright

\section{W. H. Sheldon}

Dr William H. Sheldon, Director of the Biological Humanics Center in Cambridge, Massachusetts, died there on 16 September 1977. Sheldon is the man who invented somatotyping-a classification of variations in human body structure, to which he related variations in temperament, in physical and mental illness, and in patterns of growth and aging.

Born in 1898 in Warwick, Rhode Island, Sheldon grew up amid woods and marshes. His work shows the imprint of his country background; of his mother who raised five children and was midwife to a village; of his father, a naturalist, breeder and judge of animals; and of his godfather William James, the psychologist and philosopher. At age 10 he was working for the state ornithologist, reporting on animals of the woods and fieldsobserving, describing, classifying. At 15 he took pride in his ability to match judges' scorings of livestock on 100point scales. As an adult he turned his naturalist's eye on human structure and behaviour.

After public school, Sheldon attended Brown University and the University of Colorado. From the University of
Chicago he received his Ph.D. in psychology in 1926, his M.D. in 1933. He taught at Northwestern University and the Universities of Chicago and Wisconsin. A two-year fellowship in Europe allowed him to study with Jung and to visit Freud and Kretschmer.

In 1938 he moved to Harvard, where he did much of his basic research, with such colleagues as S. S. Stevens, the experimental psychologist, and E. A. Hooton, the physical anthropologist. During World War II he served as lieutenant colonel in the Army Medical Corps. From 1947 until 1959 he was Director of the Constitution Labora- 